\title{
Hotline update of clinical trials and registries presented at the American College of Cardiology Congress 2010: ACCORD, INVEST, NAVIGATOR, RACE II, SORT OUT III, CSP-474, DOSE, ASPIRE and more
}

\author{
C. Jacobshagen $\cdot$ D. Westermann $\cdot$ C. Holubarsch • \\ M. Böhm
}

Received: 26 March 2010/ Accepted: 29 March 2010/Published online: 16 April 2010

(C) The Author(s) 2010. This article is published with open access at Springerlink.com

\begin{abstract}
This article gives an overview on a number of novel clinical trials in the field of cardiovascular medicine, which were presented during the Late Breaking Clinical Trial Sessions at the 59th annual meeting of the American College of Cardiology in Atlanta, USA, from 14th March to 16th March 2010. The data were presented by leading experts in the field with relevant positions in the trials. These comprehensive summaries should provide the readers with the most recent data on diagnostic and therapeutic developments in cardiovascular medicine similar as previously reported (Schirmer SH, van der Laan AM, Bohm M, Mahfoud F in Clin Res Cardiol 98:691-699, 2009; Maier LS, Schirmer SH, Walenta K, Jacobshagen C, Bohm M in Clin Res Cardiol 98:413-419, 2009).
\end{abstract}

C. Jacobshagen $(\bowtie)$

Georg-August-Universität Göttingen, Herzzentrum,

Abt. Kardiologie und Pneumologie, Robert-Koch-Str. 40,

37075 Göttingen, Germany

e-mail: jacobshagen@med.uni-goettingen.de

D. Westermann

Charité-Universitätsmedizin Berlin, Campus Benjamin Franklin,

Abt. Kardiologie und Pneumologie, Hindenburgdamm 30,

12200 Berlin, Germany

C. Holubarsch

Park-Klinikum Bad Krozingen, Herbert-Hellmann-Allee,

79189 Bad Krozingen, Germany

\section{Böhm}

Universitätsklinikum des Saarlandes, Klinik für Innere Medizin III, Kardiologie, Angiologie und Internistische Intensivmedizin, Kirrberger Str., 66421 Homburg, Germany
Keywords ACCORD - INVEST - NAVIGATOR ·

RACE II · SORT OUT III · DOSE · ASPIRE · CSP-474 ·

Dual antiplatelet therapy $\cdot$ Surgical ventricular reconstruction

\section{ACCORD}

In June 2001 the ACCORD (The Action to Control Cardiovascular Risk in Diabetes) study was started to answer three burning questions for diabetic patients:

1. Is more intensive blood glucose lowering strategy (targeting a glycated hemoglobin level below 6.0\%) superior to less aggressive therapy (targeting a level from 7.0 to $7.9 \%)$ ?

2. Is a combination therapy with a statine plus a fibrate more beneficial than a statin monotherapy?

3. Can an intensive blood pressure lowering therapy (targeting normal systolic blood pressure values, i.e., $<120 \mathrm{mmHg}$ ) be more successful in preventing cardiovascular endpoints than a standard therapy targeting systolic blood pressure of less than $140 \mathrm{mmHg}$ ?

In order to answer these three questions, a double $2 \times 2$ factorial design was used (Fig. 1). 10,251 patients with diabetes mellitus (median $\mathrm{HbA} 1 \mathrm{c}$ of $8.1 \%$ ) and either a cardiovascular disease or at least two additional risk factors were recruited in 77 clinical centers across the United States and Canada, a clinical trial which was sponsored by the National Heart, Lung, and Blood Institute (NHLBI). After a mean duration of follow-up of 3.5 years, a glucose control arm of the study was discontinued: Although the primary endpoint, i.e., the composite of nonfatal myocardial infarction, nonfatal stroke, or death from cardiovascular cause, showed no significant difference, death from 
any cause was significantly $(P=0.04)$ increased by $22 \%$ in the intensive-therapy group. These results were published in 2008 [3]. In the first late breaking clinical trial session of the ACC 2010 in Atlanta/USA the two ongoing ACCORD studies were presented.

\section{ACCORD lipid study}

Henry Ginsberg (Columbia University College of Physician Surgeons, New York) reported on the result of the lipid lowering arm (Fig. 1). In this arm of the trial, patients were randomized to fenofibrate (starting dose $160 \mathrm{mg}$ ) and placebo in addition to open-labeled simvastatin [4]. This treatment had no significant effect on LDL-cholesterol as compared to placebo, but significantly increased HDLcholesterol by about $1 \mathrm{mg} / \mathrm{dl}$ and significantly decreased triglycerides by $26 \mathrm{mg} / \mathrm{dl}$ as compared to placebo, respectively. This change was achieved in diabetic patients with a baseline of a median value of $162 \mathrm{mg} / \mathrm{dl}$ triglyceride. The treatment was safe as shown by creatine kinase as well as liver enzymes measurements. Although there was a slight increase in the serum creatinine levels, no increase was seen regarding the incidence of both hemodialysis and endstage renal disease. In contrast, there was a lower incidence of microalbuminuria and macroalbuminuria in the treatment group. Significant changes were observed neither in the primary endpoint (nonfatal myocardial, nonfatal stroke, and death of cardiovascular cause) nor in the secondary endpoints. Only in a subgroup of patients, who had a triglycerides level of more than $204 \mathrm{mg} / \mathrm{dl}$ and an HDL-cholesterol level of less than $34 \mathrm{mg} / \mathrm{dl}$, a tendency $(P=0.057)$ for a reduction of the primary endpoint $(-28 \%)$ was observed. The following conclusions can be made from the results and the vivid discussion:

1. Combination therapy of simvastatin and fenofibrate is safe.

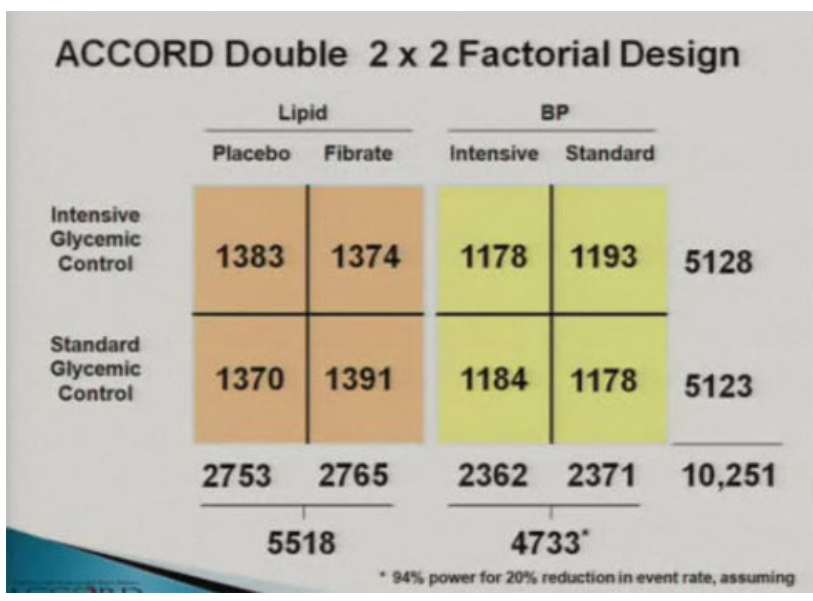

Fig. 1 ACCORD. $2 \times 2$ factorial design
2. General treatment of all diabetic patients with simvastatin plus fenofibrate cannot be recommended.

3. Patients with high triglycerides and low HDL-cholesterol may benefit from such a combination therapy. Whether this is true has to be investigated in a separate trial (presenter: Henry Ginsberg, New York, USA).

\section{ACCORD blood pressure trial}

In the second presentation of the late breaking clinical trials session, W.C. Cushmann (Veterans Affairs Medical Center, Memphis, Tennessee) presented the results of the intensive blood-pressure control arm of the ACCORD study. In this study arm (Fig. 1), 4,733 patients were randomly assigned to an intensive therapy with a target systolic blood pressure of less than $120 \mathrm{mmHg}$ or a standard antihypertensive regime targeting a systolic blood pressure of $140 \mathrm{mmHg}$ [5]. The mean follow-up was 4.7 years. The ACCORD blood pressure trial was a nonblinded trial; patients in the standard-therapy groups had a lower exposure to antihypertensive drugs (2.1) as compared to the intensive-therapy group (3.4). This resulted in a decrease of systolic blood pressure with an average between groups difference of $14.2 \mathrm{mmHg}$. The average diastolic blood difference was $6.1 \mathrm{mmHg}$. Regarding safety, the intensivetherapy groups had significantly more adverse events: higher rates of hypokalemia and increase in serum creatinine, although symptoms of orthostatic hypotension were similar between the two groups. The primary outcome, again the composite of nonfatal myocardial infarction, nonfatal stroke, and cardiovascular death, was not significantly different between the two treatment groups. Also, no significant differences were found for the secondary outcomes nonfatal infarction and death from cardiovascular disease, whereas the difference in the rate of nonfatal stroke was significant $(P<0.03)$ in favor of the more intensive treatment. The following conclusions were drawn from these results and discussed:

1. In diabetic patients a systolic blood pressure target of $120 \mathrm{mmHg}$ is not superior in preventing major cardiovascular events as compared to a target of $140 \mathrm{mmHg}$.

2. The finding that intensive blood pressure control may reduce nonfatal (and fatal) stroke is in accordance with two metaanalyses $[6,7]$. However, assuming the result would be real, the number needed to treat to prevent one stroke over the course of 5 years was 89 .

3. Regarding serious adverse events, patients treated more intensively showed more often hyperkalemia, increase in creatinine, and decrease in glomerular filtration rate (presenter: William C. Cushman, Memphis, USA). 


\section{INVEST}

A further blood-pressure trial was presented by Rhonda Cooper-Dehoff (University of Florida, Gainesville, USA): rethinking lower blood-pressure goals for diabetics with documented coronary artery disease-findings from the INVEST (INternational VErapamil SR, Trandolapril) study. This study was undertaken because evidence which supports systolic blood pressure values of less than $130 \mathrm{mmHg}$ is lacking especially in diabetic patients with coronary artery disease. In the overall INVEST-trial 22,576 patients participated. From these CAD patients, 6,400 patients suffered from diabetes and were included in the presented subgroup analysis. Blood pressure control was achieved by randomization to verapamil SR, trandalopril, and HCT or atenolol, HCT and trandalopril with trandalopril recommended to diabetic patients. Patients were divided into three groups according to their mean ontreatment systolic blood pressure: the tight control group with values lower than $130 \mathrm{mmHg}$, the usual control groups with values higher than $130 \mathrm{mmHg}$ and lower than $140 \mathrm{mmHg}$, and the not controlled group with values higher than $140 \mathrm{mmHg}$. The primary outcome, i.e., the composite of all-cause mortality, nonfatal myocardial infarction or nonfatal stroke, was highest in the not controlled group $(19.8 \%)$, and significantly $(P<0.0001)$ lower in the usual control group (12.6\%) and the tight control group (12.7\%; Table 1). Interestingly, all-cause mortality was significantly $(<0.031)$ higher in the tight control group as compared to the usual control group (Table 1). In addition, an analysis was performed for patients with systolic blood pressure lower than $120 \mathrm{mmHg}$ showing the highest all-cause mortality in the group with lowest systolic blood pressure (hazard ratio above 2.0 when systolic blood pressure was lower than $110 \mathrm{mmHg}$ ) (presenter: Rhonda M. Cooper-Dehoff, Gainesville, USA).

\section{NAVIGATOR}

Robert Califf (Duke University, Durham, NC) reported on the NAVIGATOR (NAteglinide and Valsartan in Impaired Glucose Tolerance Outcomes Research) trial; it is neither known of whether the short acting insulin secretagogue nateglinide nor angiotensin-receptor-blocker valsartan may reduce the risk to develop diabetes and cardiovascular events in patients with impaired glucose tolerance (socalled prediabetes) $[8,9]$. In the presented trial, 9,306 participants with impaired glucose tolerance and cardiovascular disease or risk factors were assigned to receive nateglinide (up to $60 \mathrm{mg}$ three times daily) or placebo in a $2 \times 2$ factorial design with valsartan or placebo. The median follow-up was 5.0 years for the development of diabetes and 6.5 years for vital status. The primary outcomes were development of diabetes and the composite of death of cardiovascular causes, nonfatal myocardial infarction, nonfatal stroke, or hospitalization for heart failure. Nateglinide had no effect, neither on the development of diabetes nor on cardiovascular events. In contrast, valsartan showed a significant $(P<0.001)$ effect by reducing the incidence of diabetes by $14 \%$ (Fig. 2), but did not reduce the rate of cardiovascular events. The effect on diabetes is in accordance with the LIFE [10] and the VALUE [11] studies in which the incidence of diabetes development, however, was a secondary endpoint (presenter: Robert M. Califf, Durham, USA).

Table 1 INVEST: outcome rates

\begin{tabular}{|c|c|c|c|c|}
\hline Outcome & $\begin{array}{l}\text { Tight control }(n=2,255) \\
\text { No. of events (events rate \%) }\end{array}$ & $\begin{array}{l}\text { Usual control } \\
(n=1,970)\end{array}$ & $\begin{array}{l}\text { Not controlled } \\
(n=2,175)\end{array}$ & $P$ value \\
\hline \multicolumn{5}{|c|}{ INVEST follow-up $(n=6,400)$} \\
\hline Primary outcome & $286(12.7)$ & $249(12.6)$ & $431(19.8)$ & $<0.0001$ \\
\hline Nonfatal MI & $29(1.3)$ & $33(1.7)$ & $67(3.1)$ & 0.008 \\
\hline Nonfatal stroke & $22(1.0)$ & $26(1.3)$ & $52(2.4)$ & 0.001 \\
\hline Total MI & $108(4.8)$ & $100(5.0)$ & $185(8.5)$ & $<0.0001$ \\
\hline Total stroke & $34(1.5)$ & $33(1.7)$ & $70(3.2)$ & 0.0001 \\
\hline All-cause mortality & $248(11.0)$ & $201(10.2)$ & $334(15.4)$ & $<0.0001$ \\
\hline Outcome & $\begin{array}{l}\text { Tight control }(n=1,389) \\
\text { No. of events (events rate \%) }\end{array}$ & $\begin{array}{l}\text { Usual control } \\
(n=1,423)\end{array}$ & $\begin{array}{l}\text { Not allowed } \\
(n=1,558)\end{array}$ & $P$ value \\
\hline \multicolumn{5}{|c|}{ Extended follow-up $(n=4,370)$} \\
\hline All-cause mortality & $270(19.4)$ & $259(18.2)$ & $370(23.7)$ & 0.01 \\
\hline
\end{tabular}


A Incidence of Diabetes

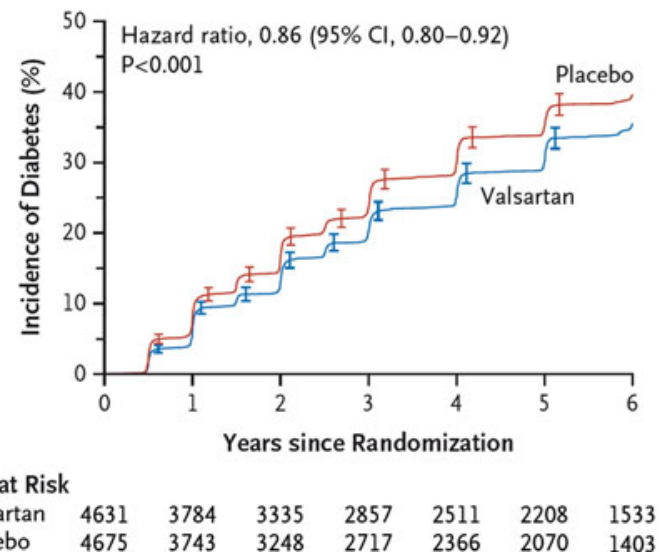

Fig. 2 NAVIGATOR. Kaplan-Meier curves for three coprimary outcomes [9]. a The incidence of diabetes, the coprimary outcome. b The coprimary extended cardiovascular outcome, a composite of death from cardiovascular causes, nonfatal myocardial infarction,

\section{RACE II}

Guidelines recommend strict rate control in patients with permanent atrial fibrillation (AF), but this is not based on clinical evidence. RACE II (Rate Control Efficacy in Permanent Atrial Fibrillation: a Comparison between Lenient versus Strict Rate Control II) was a prospective, multicenter, randomized, open-label, noninferiority trial designed to compare two rate-control strategies in patients with permanent $\mathrm{AF}$ [12]. 614 patients were assigned to undergo a lenient rate-control strategy (resting heart rate $<110$ beats per minute) or a strict rate-control strategy (resting heart rate $<80$ beats per minute and heart rate during moderate exercise $<110$ beats per minute). The primary outcome was a composite of death from any cause, hospitalization for heart failure, and stroke, systemic embolism, bleeding, and life-threatening arrhythmic events. To achieve the target heart rates, patients were given beta-blockers, calcium-channel blockers and/or digoxin. During follow-up ranging from 2 to 3 years, the primary outcome occurred in $12.9 \%$ of patients in the lenient-control group, as compared with $14.9 \%$ of patients in the strict-control group $(P<0.0001$ for the prespecified noninferiority margin; Fig. 3). More patients in the lenientcontrol group met the heart rate targets ( 97.7 vs. $67.0 \%$ in the strict-control group; $P<0.001)$ with fewer total visits (75 vs. $684 ; P<0.001$ ). In conclusion, lenient rate control was noninferior to strict rate control in the prevention of major cardiovascular events in patients with permanent AF. Furthermore, for both patients and health care providers, lenient rate control is more convenient, since fewer outpatient visits and examinations are needed. The clinical implications of RACE II are that lenient rate control may be adopted as a first-choice rate-control strategy in patients
B Extended Cardiovascular Outcome

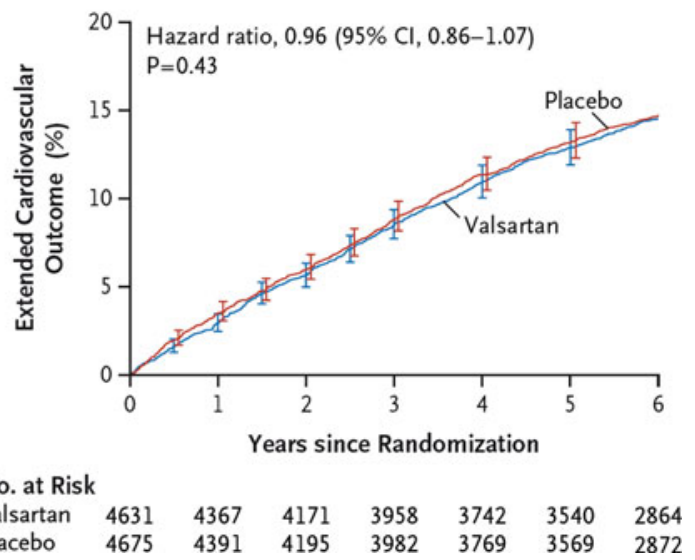

nonfatal stroke, hospitalization for heart failure, arterial revascularization, or hospitalization for unstable angina. All $P$ values are twosided. The vertical bars indicate $95 \%$ confidence intervals

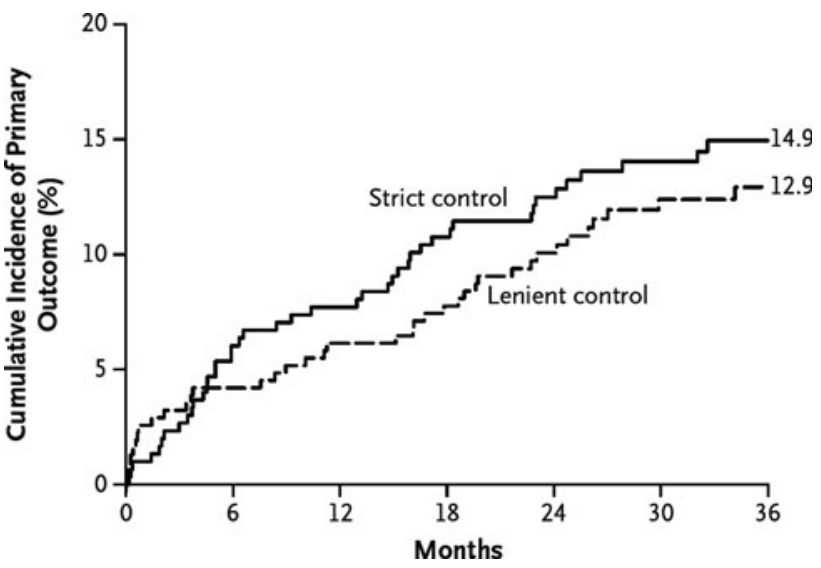

Fig. 3 RACE II. Kaplan-Meier estimates of the cumulative incidence of the primary outcome, according to treatment group [12]. The numbers at the end of the Kaplan-Meier curves is the estimated cumulative incidence of the primary outcome at 3 years

with permanent AF. Neverthless, since the study was relatively small, large scale studies have to reveal the long term effect of lenient rate vs strict control in patients with $\mathrm{AF}$ in more detail (presenter: Isabelle C. Van Gelder, Groningen, The Netherlands).

\section{SORT OUT III}

Drug-eluting stents (DES) are widely used because, compared with bare-metal stents, in-stent restenosis and the need for repeat revascularization are reduced. But are there clinically meaningful differences between DES? SORT OUT III (The Danish Organization for Randomized Trials with Clinical Outcome: efficacy and safety of zotarolimuseluting and sirolimus-eluting coronary stents in routine clinical care) was a multicenter, single-blind, randomized 
Table 2 SORT OUT III: clinical outcomes [13]

\begin{tabular}{|c|c|c|c|c|}
\hline & $\begin{array}{l}\text { Zotarolimus-eluting } \\
\text { stent }(n=1,162)\end{array}$ & $\begin{array}{l}\text { Sirolimus-eluting } \\
\text { stent }(n=1,170)\end{array}$ & $\begin{array}{l}\text { Hazard ratio } \\
(95 \% \mathrm{CI})\end{array}$ & $P$ value \\
\hline \multicolumn{5}{|l|}{ Events at 30 days $^{\mathrm{a}}$} \\
\hline All-cause mortality & $4(<1 \%)$ & $4(<1 \%)$ & $1.01(0.25-4.02)$ & 0.99 \\
\hline Cardiac death & $4(<1 \%)$ & $4(<1 \%)$ & $1.01(0.25-4.02)$ & 0.99 \\
\hline Myocardial infarction & $9(1 \%)$ & $2(<1 \%)$ & $4.53(0.98-21.0)$ & 0.053 \\
\hline Target vessel revascularization & $10(1 \%)$ & $8(1 \%)$ & $1.26(0.50-3.19)$ & 0.63 \\
\hline Target lesion revascularization & $8(1 \%)$ & $5(<1 \%)$ & $1.61(0.53-4.92)$ & 0.40 \\
\hline \multicolumn{5}{|l|}{ Events at 9 months ${ }^{\mathrm{a}}$} \\
\hline Composite endpoint ${ }^{\mathrm{b}}$ & $72(6 \%)$ & $34(3 \%)$ & $2.15(1.43-3.23)$ & 0.0002 \\
\hline All-cause mortality & $25(2 \%)$ & $18(2 \%)$ & $1.40(0.76-2.56)$ & 0.28 \\
\hline Cardiac death & $12(1 \%)$ & $6(1 \%)$ & $2.01(0.76-5.36)$ & 0.16 \\
\hline Myocardial infarction & $18(2 \%)$ & $4(<1 \%)$ & $4.55(1.54-13.4)$ & 0.006 \\
\hline Target vessel revascularization & $62(5 \%)$ & $28(2 \%)$ & $2.25(1.44-3.51)$ & 0.0004 \\
\hline Target lesion revascularization & $50(4 \%)$ & $12(1 \%)$ & $4.25(2.26-7.97)$ & $<0.0001$ \\
\hline \multicolumn{5}{|l|}{ Events at 18 months $^{\mathrm{c}}$} \\
\hline Composite endpointb & $113(10 \%)$ & $53(5 \%)$ & $2.19(1.58-3.04)$ & $<0.0001$ \\
\hline All-cause mortality & $51(4 \%)$ & $32(3 \%)$ & $1.61(1.03-2.50)$ & 0.035 \\
\hline Cardiac death & $18(2 \%)$ & $12(1 \%)$ & $1.51(0.73-3.14)$ & 0.27 \\
\hline Myocardial infarction & $24(2 \%)$ & $11(1 \%)$ & $2.22(1.09-4.53)$ & 0.029 \\
\hline Target vessel revascularization & $92(8 \%)$ & $39(3 \%)$ & $2.42(1.67-3.52)$ & $<0.0001$ \\
\hline Target lesion revascularization & $71(6 \%)$ & $20(2 \%)$ & $3.66(2.23-6.01)$ & $<0.0001$ \\
\hline
\end{tabular}

all-comer superiority trial to compare the efficacy and safety of the zotarolimus-eluting stent versus the sirolimuseluting stent in patients with chronic stable coronary artery disease or acute coronary syndromes [13]. The primary endpoint was a composite of cardiac death, myocardial infarction, and target vessel revascularization. 2,332 patients were included (1,162 received zotarolimus-eluting stents, 1,170 received sirolimus-eluting stents). In contrast to many other studies, patients with complex lesions (e.g., bifurcations, ostial lesions, and chronic total occlusions) were included. At 9 months, the primary endpoint had occurred in a significant higher proportion of patients treated with the zotarolimus-eluting stent than those treated with the sirolimus-eluting stent [72 (6\%) vs. 34 (3\%); HR $2.15,95 \%$ CI $1.43-3.23 ; P=0.0002$; Table 2]. At 18-month follow-up, this difference was sustained [113 (10\%) vs. 53 (5\%); HR 2.19, 95\% CI 1.58-3.04; $P<$ 0.0001]. For patients receiving the zotarolimus-eluting stent and those receiving the sirolimus-eluting stent, allcause mortality was similar at 9-month follow-up, but was significantly different at 18-month follow-up [51 (4\%) vs. 32 (3\%); HR 1.61, 95\% CI 1.03-2.50; $P=0.035$; Table 2). The authors conclude that the sirolimus-eluting stent is superior to the zotarolimus-eluting stent for patients receiving routine clinical care. Differences in results between this and previously published trials may be due to the all-comers design of the current study and the fact that it was powered to assess clinical endpoints (presenter: Michael Maeng, Aarhus, Denmark).

\section{Duration of dual antiplatelet therapy after implantation of drug-eluting stents}

Early discontinuation of dual antiplatelet therapy has been identified as a risk factor for late stent thrombosis in patients with drug-eluting stents (DES) [14]. The optimal duration of dual antiplatelet therapy is unclear. The current analysis merged data from two concurrent randomized, clinical multicenter trials (REAL-LATE and ZEST-LATE) [15]. A total of 2,701 patients who were event-free for at least 12 months after DES implantation were randomly assigned to receive clopidogrel plus aspirin or aspirin alone. The median duration of follow-up was 19.2 months. There was no significant benefit associated with clopidogrel continuation (clopidogrel plus aspirin) as compared 

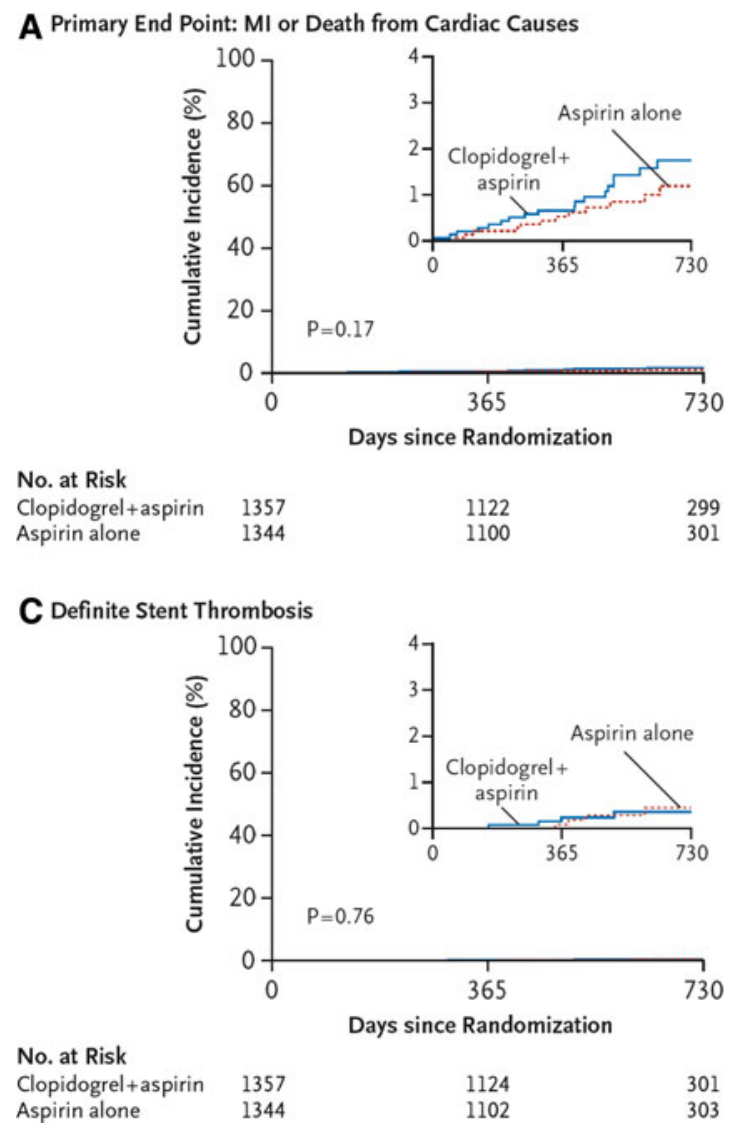

Fig. 4 Dual antiplatelet therapy. Cumulative incidence of the primary end point and selected secondary end points, according to treatment group [15]. Cumulative-incidence curves are shown for the primary end point of myocardial infarction $(M I)$ or death from cardiac

with clopidogrel discontinuation (aspirin alone) after 12 months, in reducing the incidence of myocardial infarction or death from cardiac causes (primary endpoint; Fig. 4) [15]. However, in the dual-therapy group as compared with the aspirin-alone group, there was a nonsignificant increase in the composite risk of myocardial infarction, stroke, or death from any cause (hazard ratio 1.73 , 95\% CI $0.99-3.00 ; P=0.051)$ and the composite risk of myocardial infarction, stroke, or death from any cause (hazard ratio 1.84, 95\% CI $0.99-3.45 ; P=0.06$; Fig. 4). However, the study had insufficient statistical power to allow a firm conclusion regarding the safety of clopidogrel discontinuation after 12 months. Additional studies addressing the use of dual antiplatelet therapy after implantation of DES are ongoing (presenter: Seung-Jung Park, Seoul, South Korea).

\section{DOSE}

The field of acute decompensated heart failure (ADHF) is plagued by virtually no evidence-based therapy [16].
B Death from Any Cause

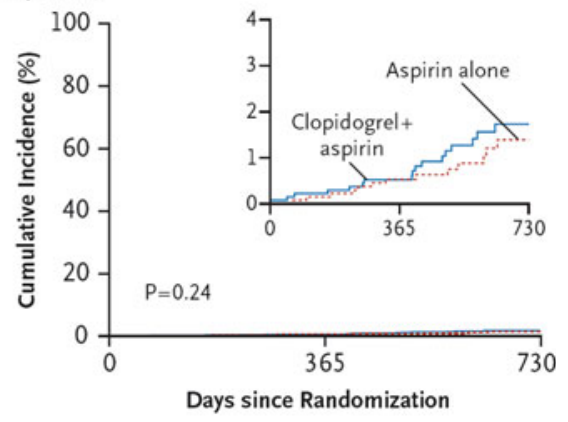

\section{No. at Risk}

$\begin{array}{llll}\text { Clopidogrel+aspirin } & 1357 & 1125 & 302\end{array}$

Aspirin alone

1344

1103

303

D MI, Stroke, or Death from Any Cause

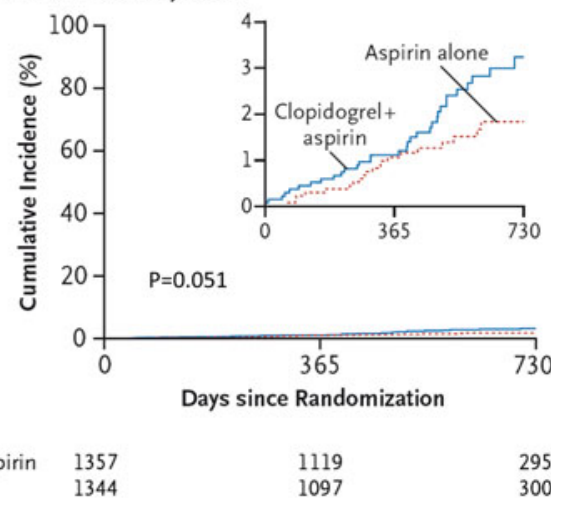

No. at Risk

$\begin{array}{llll}\text { Clopidogrel+aspirin } & 1357 & 1119 & 295 \\ \text { Aspirin alone } & 1344 & 1097 & 300\end{array}$

causes (a), death from any cause (b), definite stent thrombosis (c), and the secondary composite end point of death from any cause, MI, or stroke (d). $P$ values were calculated with the use of the log-rank test

Even the use of loop diuretics, the main treatment option in most patients in clinical routine, is not evidence guided in regard to dose and route of administration. Based on observational data, many clinicians believe that highdose loop diuretic admitted as a bolus would cause more kidney damage than lower dosages as a continuous infusion. The DOSE (Diuretic Optimization Strategies Evaluation) trial separately randomized its 308 predominantly male patients with a prior diagnosis of chronic heart failure and daily outpatient use of oral loop diuretics $(80-240 \mathrm{mg}$ ) for at least 1 month to receive intravenous furosemide at "low" versus "high" doses and in a continuous infusion versus a bolus every $12 \mathrm{~h}$. "Low dose" corresponded to the patient's oral dose, and "high dose" meant 2.5 times the oral dose. Patients presenting with a low systolic blood pressure (below $90 \mathrm{mmHg}$ ) and the anticipated need for coronary angiography were excluded. Symptoms as gauged by patient global assessment score at $72 \mathrm{~h}$, the primary efficacy end point, were not significantly different between the intermittent and continuous dosing groups $(P=0.47)$. The high-dose strategy trended toward greater symptom 
improvement $(P=0.06)$. There was also no significant difference in the primary safety endpoint, change of serum creatinine after $72 \mathrm{~h}$ between all groups. The secondary endpoints favored higher doses with no change between bolus of continuous infusion with an increased risk of worsening of renal function, defined as a $>3 \mathrm{mg} /$ dl rise in creatinine. Nevertheless, 60 days after inclusion, renal dysfunction was similar in all treatment arms but interestingly still higher compared to before the episode of ADHF. Moreover, although not powered for clinical events, there was no difference in re-hospitalization or death favoring any group. Therefore, the authors conclude that bolus administration with higher doses may be convenient, safe as well as efficient in patients with ADHF (presenter: Gary Michael Felker, Durham, USA).

\section{ASPIRE}

The ASPIRE (Aliskiren Study in Post-MI Patients to Reduce REmodeling) study addressed the use of the direct renin inhibitor aliskiren as an add-on to conventional therapy in patients post-myocardial infarction with low ejection fraction. The authors included 820 patients and randomized them to placebo or aliskiren (titrated up to $300 \mathrm{mg}$ ) for 36 weeks. The inclusion criteria selected patients on an ARB or an ACE-I (but no patients on an ARB combined with an ACE-I) after an acute myocardial infarction within 7-42 days with an EF below 45\%. There was no significant improvement in the primary endpoint, the change in the LV endsystolic volume between placebo and aliskiren $(-3.5 \pm 16.3$ vs. $-4.4 \pm 16.8 ; P=0.44)$ after 36 weeks. Nevertheless, double RAAS inhibition with aliskiren as an add-on on top of conventional therapy increased the risk of adverse events significantly with increased renal dysfunction (creatinine $>2$ and $<3 \mathrm{mg} / \mathrm{dl}$, 3 vs. 10 patients; $P=0.09$ ), hypotension and hyperkalemia (5 vs. 22 patients; $P<0.001$ ) although there was no significant change in serious adverse events (creatinine above $3 \mathrm{mg} / \mathrm{dl}$ ). The panel discussed a "worrysome trend towards increased mortality in the aliskiren group" although this study was not powered to address clinical outcome, as stressed by the main ASPIRE author Scott Solomon. Nevertheless, while ongoing outcome studies with aliskiren in patients with heart failure and diabetic kidney disease are on their way to completion, this study does not provide evidence for the use of aliskiren as an add-on post-myocardial infarction. Moreover, it is in line with other findings demonstrating increased adverse events without additional benefit after double RAAS inhibition in the ONTARGET trial [17] (presenter: Scott D. Solomon, Boston, USA).

\section{STICH (substudy)}

While the data of the original STICH (Surgical Treatment for Ischemic Heart Failure) trial [18] showed no evidence for a benefit for additional surgical ventricular reconstruction (SVR) during CABG for patients with ischemic cardiomyopathy, this year a paired core laboratory studies was presented to determine whether any magnitude of postoperative change in LV ESVI might identify a subgroup of CABG + SVR patients who have increased survival when compared to patients undergoing CABG alone. The analysis was limited to the 595 patients who had accurate preoperative and 4-month postoperative measures of their end-systolic volume. No significant difference was found comparing groups with preoperative endsystolic volume index (ESVI) below 60, between 60 and 90 and above $90 \mathrm{ml} / \mathrm{m}^{2}$. Many surgeons assumed that patients whose baseline end-systolic volume index was especially high $\left(>90 \mathrm{ml} / \mathrm{m}^{2}\right)$ would benefit most from SVR, the STICH author Dr Robert Michler said. However, this analysis found the opposite with a nonsignificant trend for improvement in patients with relatively small ventricle (group below $60 \mathrm{ml} / \mathrm{m}^{2}$ ). Therefore, SVR seems to be no option for general CABG surgery (presenter: Robert E. Michler, Durham, USA).

\section{CSP-474}

The left internal mammary artery has been demonstrated to be superior to the saphenous vein for coronary artery bypass graft (CABG) procedures. The patency of radialartery grafts is unclear. CSP-474 was a prospective, randomized, multicenter-study to compare the patency of radial-artery grafts with saphenous-vein grafts. 733 patients were enrolled in 11 VA medical centers between 2003 and 2008. Follow-up coronary artery angiography demonstrated a 1-week patency of $99 \%$ for the radial-artery graft and $97 \%$ for the venous graft. After 1 year, the patency for both types of grafts was $89 \%$. An analysis based on location of the graft showed no differences based on what type of graft was used. Of note, radial grafts were more likely than saphenous grafts to show early signs of disease, with $8 \%$ of radial grafts showing the "string sign" compared with just $1 \%$ of saphenous grafts. A subanalysis looking at the low numbers of patients treated off-pump hinted that patency was no different in radial grafts placed on- or offpump; by contrast, patency rates were lower in saphenous grafts placed off-pump. And in another intriguing finding, endoscopic harvesting - which has previously been linked to worse patency-was linked to worse patency in the saphenous grafts, but not in the radial grafts. A cost analysis showed that, overall, costs were nearly identical 
between the two groups, at around $\$ 42,000$ to $\$ 43,000$. Surgical costs, however, were slightly higher in the radial group. In conclusion, there were no differences in the radial-artery graft versus saphenous-vein grafts at 1 year. However, since cardiac surgery is a treatment used for a long-term outcome, it is necessary to look at long-term patency (presenter: Steve Goldmann, Tucson, USA).

Open Access This article is distributed under the terms of the Creative Commons Attribution Noncommercial License which permits any noncommercial use, distribution, and reproduction in any medium, provided the original author(s) and source are credited.

\section{References}

1. Schirmer SH, van der Laan AM, Bohm M, Mahfoud F (2009) Hotlines and clinical trial updates presented at the European Society of Cardiology Meeting 2009: data from RE-LY, PLATO, MADIT-CRT, PROTECT, SYNTAX, TRITON and more. Clin Res Cardiol 98:691-699

2. Maier LS, Schirmer SH, Walenta K, Jacobshagen C, Bohm M (2009) Hotline update of clinical trials and registries presented at the German Cardiac Society Meeting 2009. Clin Res Cardiol 98:413-419

3. The Action to Control Cardiovascular Risk in Diabetes Study Group (2008) Effects of Intensive Glucose Lowering in Type 2 Diabetes. N Engl J Med 358:2545-2559

4. The ACCORD Study Group (2010) Effects of combination lipid therapy in type 2 diabetes mellitus. N Engl J Med [Epub ahead of print]

5. The ACCORD Study Group (2010) Effects of intensive bloodpressure control in type 2 diabetes mellitus. N Engl J Med [Epub ahead of print]

6. MacMahon S, Peto R, Cutler J, Collins R, Sorlie P, Neaton J, Abbott R, Godwin J, Dyer A, Stamler J (1990) Blood pressure, stroke, and coronary heart disease. Part 1 , prolonged differences in blood pressure: prospective observational studies corrected for the regression dilution bias. Lancet 335:765-774

7. Law MR, Morris JK, Wald NJ (2009) Use of blood pressure lowering drugs in the prevention of cardiovascular disease: metaanalysis of 147 randomised trials in the context of expectations from prospective epidemiological studies. BMJ 338:b1665

8. The NAVIGATOR Study Group (2010) Effect of nateglinide on the incidence of diabetes and cardiovascular events. N Engl J Med [Epub ahead of print]

9. The NAVIGATOR Study Group (2010) Effect of valsartan on the incidence of diabetes and cardiovascular events. N Engl J Med [Epub ahead of print]

10. Dahlof B, Devereux RB, Kjeldsen SE, Julius S, Beevers G, de FU, Fyhrquist F, Ibsen H, Kristiansson K, Lederballe-Pedersen O,
Lindholm LH, Nieminen MS, Omvik P, Oparil S, Wedel H (2002) Cardiovascular morbidity and mortality in the losartan intervention for endpoint reduction in hypertension study (LIFE): a randomised trial against atenolol. Lancet 359:995-1003

11. Julius S, Kjeldsen SE, Weber M, Brunner HR, Ekman S, Hansson L, Hua T, Laragh J, McInnes GT, Mitchell L, Plat F, Schork A, Smith B, Zanchetti A (2004) Outcomes in hypertensive patients at high cardiovascular risk treated with regimens based on valsartan or amlodipine: the VALUE randomised trial. Lancet 363:2022-2031

12. Van Gelder IC, Groenveld HF, Crijns HJ, Tuininga YS, Tijssen JG, Alings AM, Hillege HL, Bergsma-Kadijk JA, Cornel JH, Kamp O, Tukkie R, Bosker HA, van Veldhuisen DJ, Van den Berg MP (2010) Lenient versus strict rate control in patients with atrial fibrillation. $\mathrm{N}$ Engl $\mathrm{J}$ Med [Epub ahead of print]

13. Rasmussen K, Maeng M, Kaltoft A, Thayssen P, Kelbaek H, Tilsted HH, Abildgaard U, Christiansen EH, Engstrom T, Krusell LR, Ravkilde J, Hansen PR, Hansen KN, Abildstrom SZ, Aaroe J, Jensen JS, Kristensen SD, Botker HE, Madsen M, Johnsen SP, Jensen LO, Sorensen HT, Thuesen L, Lassen JF (2010) Efficacy and safety of zotarolimus-eluting and sirolimus-eluting coronary stents in routine clinical care (SORT OUT III): a randomised controlled superiority trial. Lancet [Epub ahead of print]

14. Capodanno D, Capranzano P, Bucalo R, Sanfilippo A, Ruperto C, Caggegi A, Ussia G, Galassi AR, Tamburino C (2009) A novel approach to define risk of stent thrombosis after percutaneous coronary intervention with drug-eluting stents: the DERIVATION score. Clin Res Cardiol 98:240-248

15. Park SJ, Park DW, Kim YH, Kang SJ, Lee SW, Lee CW, Han KH, Park SW, Yun SC, Lee SG, Rha SW, Seong IW, Jeong MH, Hur SH, Lee NH, Yoon J, Yang JY, Lee BK, Choi YJ, Chung WS, Lim DS, Cheong SS, Kim KS, Chae JK, Nah DY, Jeon DS, Seung KB, Jang JS, Park HS, Lee K (2010) Duration of dual antiplatelet therapy after implantation of drug-eluting stents. $\mathrm{N}$ Engl J Med [Epub ahead of print]

16. Gorelik O, moznino-Sarafian D, Shteinshnaider M, Alon I, Tzur I, Sokolsky I, Efrati S, Babakin Z, Modai D, Cohen N (2009) Clinical variables affecting survival in patients with decompensated diastolic versus systolic heart failure. Clin Res Cardiol 98:224-232

17. Mann JF, Schmieder RE, McQueen M, Dyal L, Schumacher H, Pogue J, Wang X, Maggioni A, Budaj A, Chaithiraphan S, Dickstein K, Keltai M, Metsarinne K, Oto A, Parkhomenko A, Piegas LS, Svendsen TL, Teo KK, Yusuf S (2008) Renal outcomes with telmisartan, ramipril, or both, in people at high vascular risk (the ONTARGET study): a multicentre, randomised, double-blind, controlled trial. Lancet 372:547-553

18. Maier LS, Baumhakel M, Bohm M (2009) Hotline sessions presented at the American College of Cardiology Congress 2009. Clin Res Cardiol 98:345-352 